\title{
Gender-based analysis of pre-residency research productivity among a current United States radiation oncology resident class
}

\author{
Shearwood McClelland III ${ }^{1}$, Blair Murphy ${ }^{2}$, Jerry J. Jaboin ${ }^{3}$, Richard C. Zellars ${ }^{1}$ \\ ${ }^{1}$ Department of Radiation Oncology, Indiana University School of Medicine, Indianapolis, IN, USA; ${ }^{2}$ Department of Radiation Oncology, Oregon \\ Health and Science University, Portland, OR, USA; ${ }^{3}$ Department of Radiation Oncology, University of Oklahoma Health Sciences Center, \\ Oklahoma City, OK, USA \\ Contributions: (I) Conception and design: S McClelland 3rd; (II) Administrative support: JJ Jaboin, RC Zellars; (III) Provision of study materials \\ or patients: None; (IV) Collection and assembly of data: S McClelland 3rd, B Murphy; (V) Data analysis and interpretation: All authors; (VI) \\ Manuscript writing: All authors; (VII) Final approval of manuscript: All authors. \\ Correspondence to: Shearwood McClelland III, MD. Department of Radiation Oncology, Indiana University School of Medicine, 535 Barnhill Drive, \\ RT 041, Indianapolis, IN 46202, USA. Email: drwood@post.harvard.edu.
}

\begin{abstract}
Background: The increasing proportion of women in medicine has not been adequately reflected in the gender distribution of radiation oncology residents. The presence of at least one pre-residency peer-reviewed publication (PRP) has been associated with radiation oncology resident choice of academic over private practice career, with no significant gender difference in the likelihood of having a PRP (McClelland et al., 2017). We sought to pursue a gender-based analysis of PRP productivity in a current junior resident class.

Methods: A list of radiation oncology residents from the graduating class of 2022 (PGY-2 academic year of 2018-2019) was obtained through internet investigation. Research productivity was calculated using PRP number, defined as the number of a resident's publications listed in PubMed (pubmed.gov) through the calendar year of residency application (2016 for this class).

Results: Of 195 residents examined from the 2022 class, 61 (31\%) were women, representing a nine percent increase from the resident class of 2016. Four-fifths of women had 1+ PRP, 31\% had dual degrees, and $18 \%$ had a $\mathrm{PhD}$. These percentages were comparable to their male counterparts, $73 \%$ with $1+\mathrm{PRP}$, $28 \%$ with dual degrees, and $15 \%$ with a $\mathrm{PhD}$. There were no statistically significant differences by gender in any of these benchmarks.

Conclusions: While slower than the overall trend of increased female representation in medicine, the proportion of women in radiation oncology residency has increased by $0.9-1.5 \%$ annually over a recent six-year span. There remain no significant differences in PRP productivity, dual degree status, or PhD status by gender.
\end{abstract}

Keywords: Gender equity; radiation oncology residents; pre-residency peer-reviewed publications (PRP); research productivity

Submitted Jul 20, 2021. Accepted for publication Oct 12, 2021.

doi: $10.21037 /$ cco-21-95

View this article at: https://dx.doi.org/10.21037/cco-21-95

\section{Introduction}

The increasing proportion of women in medicine has not been adequately reflected in the gender distribution of residents, particularly in highly competitive subspecialties such as neurosurgery and (prior to 2019) radiation oncology $(1,2)$. In both radiation oncology and neurosurgery, the presence of at least one pre-residency peer-reviewed publication (PRP) has been associated with future resident choice of academic over private practice career, with no significant gender difference in the likelihood of having a PRP in either field $(3,4)$. We sought to pursue a genderbased analysis of PRP productivity in a current radiation 


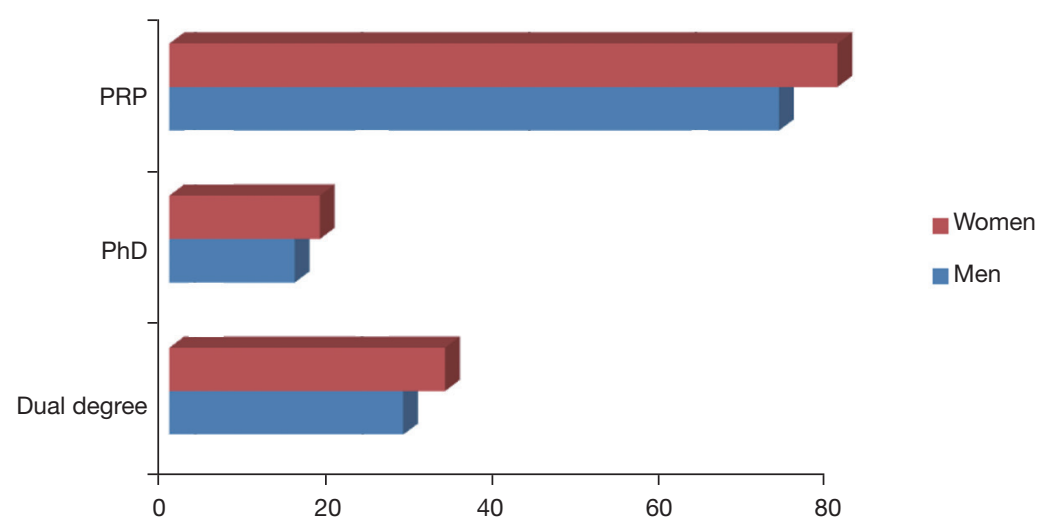

Figure 1 Depiction of research demographics comparing the radiation oncology residency class of 2022 by gender (percentages depicted). There were no statistically significant differences between male and female residents. PRP, at least one pre-residency peer-reviewed publication; $\mathrm{PhD}$, presence of a $\mathrm{PhD}$.

oncology resident class. We present the following article in accordance with the MDAR reporting checklist (available at https://dx.doi.org/10.21037/cco-21-95).

\section{Methods}

A radiation oncology resident list from the graduating class of 2022 (PGY-2 academic year of 2018-2019) was collected by referencing participant names listed on program websites; confirmation was pursued through communication with residency program coordinators and directors as needed. In addition to gender, demographics included dual degree status and presence/absence of a PhD. Research productivity was calculated using PRP number, defined as the number of a resident's publications listed in PubMed (pubmed.gov) through the calendar year of residency application (2016 for the class of 2022), as previously described $(3,4)$.

\section{Statistical analysis}

Statistical analysis was conducted using Fisher's exact test, with significance assigned at $\mathrm{P}<0.05$ (GraphPad Software, San Diego, USA). For variables reaching statistical significance, odds ratios were calculated with an accompanying 95\% confidence interval (MedCalc Software, Belgium).

\section{Results}

Of 195 residents examined from the 2022 class, 61 (31.3\%) were women, representing a 5-9 percent increase from the resident class of 2016 based on the available literature: one publication comprised of 163 residents revealed a $22.1 \%$ rate of women (4) and another publication comprised of 182 residents revealed a $25.8 \%$ rate of women (5). Fourfifths of female residents (80\%) had at least one PRP, $31 \%$ had dual degrees, and $18 \%$ had a $\mathrm{PhD}$. These percentages were comparable to their male counterparts, $75 \%$ of whom had at least one PRP, 28\% who had dual degrees, and $15 \%$ who had a PhD (Figure 1). Specific analyses revealed no statistically significant differences by gender in any of these benchmarks $(\mathrm{P}>0.05)$.

\section{Discussion}

The results from this study help to confirm a fact already well-established in the peer-reviewed literature: there is no significant difference in research productivity between male and female radiation oncology residents either before or during residency $(4,6-9)$. The fact that the examined population is comprised of extremely recent participants in the resident match (2017) serves as validation that there remains no legitimate reason for gender-based bias in the perception of radiation oncology resident research productivity.

Although the female representation of radiation oncology residents remains behind that of less competitive subspecialties such as hematology oncology (10), the $5.5-9.2 \%$ increase in female radiation oncology resident representation over the recent six-year period in this study $(4,5)$ averages to an approximate $0.9-1.5 \%$ increase per 
year, which is $3-5$ times the $0.3 \%$ per year increase from a recent study spanning three decades (10). This may be evidence that the recent rate of female representation growth in radiation oncology residency is increasing faster than historic levels. That being said, the current rate of $31 \%$ remains far less than the representation of women in medical schools, which in 2017 outnumbered men for the first time (11).

Limitations to this study include its inability to capture every radiation oncology resident from the class of 2022, and its reliance on PubMed to accurately reflect PRP for each resident; the increasing popularity of open-access journals over the past decade (many of which are not listed in PubMed) increases the likelihood of an applicant publishing in such a journal yet not having that publication counted in their PRP tally. The focus of this study on United States programs limits its applicability globally.

In conclusion, while slower than the overall trend of increased female representation in medicine, the proportion of women in radiation oncology residency has increased by approximately $0.9-1.5 \%$ per year over a recent six-year span. The results of this study show that as previously demonstrated for the class of 2016, there is no significant difference by gender in PRP productivity for the class of 2022 (Figure 1). Within the class of 2022 there are also no significant gender differences in the likelihood of dual degree status or $\mathrm{PhD}$ status. Further study will be needed to determine how these findings manifest in career choice following graduation.

\section{Acknowledgments}

Funding: None.

\section{Footnote}

Reporting Checklist: The authors have completed the MDAR checklist. Available at https://dx.doi.org/10.21037/cco-21-95

Data Sharing Statement: Available at https://dx.doi. org/10.21037/cco-21-95

Conflicts of Interest: All authors have completed the ICMJE uniform disclosure form (available at https://dx.doi. org/10.21037/cco-21-95). Dr. SM III severs as the unpaid editorial board member of Chinese Clinical Oncology. The other authors have no conflicts of interest to declare.
Ethical Statement: The authors are accountable for all aspects of the work in ensuring that questions related to the accuracy or integrity of any part of the work are appropriately investigated and resolved. The study was conducted in accordance with the Declaration of Helsinki (as revised in 2013). This study was exempt from IRB review at Indiana University.

Open Access Statement: This is an Open Access article distributed in accordance with the Creative Commons Attribution-NonCommercial-NoDerivs 4.0 International License (CC BY-NC-ND 4.0), which permits the noncommercial replication and distribution of the article with the strict proviso that no changes or edits are made and the original work is properly cited (including links to both the formal publication through the relevant DOI and the license). See: https://creativecommons.org/licenses/by-nc-nd/4.0/.

\section{References}

1. Renfrow JJ, Rodriguez A, Liu A, et al. Positive trends in neurosurgery enrollment and attrition: analysis of the 2000-2009 female neurosurgery resident cohort. J Neurosurg 2016;124:834-9.

2. Ahmed AA, Egleston B, Holliday E, et al. Gender trends in radiation oncology in the United States: a 30-year analysis. Int J Radiat Oncol Biol Phys 2014;88:33-8.

3. McClelland S 3rd. Pre-residency peer-reviewed publications are associated with neurosurgery resident choice of academic compared to private practice careers. J Clin Neurosci 2010;17:287-9.

4. McClelland S 3rd, Thomas CR Jr, Wilson LD, et al. Association of preresidency peer-reviewed publications with radiation oncology resident choice of academic versus private practice career. Pract Radiat Oncol 2017;7:364-7.

5. Rowley JP, Sindhu KK, Smith WH, et al. Radiation Oncology Resident Research Productivity in the United States: 2015 to 2019. Int J Radiat Oncol Biol Phys 2021;109:1111-8.

6. Rana S, Holliday EB, Jagsi R, et al. Scholastic activity among radiation oncology residents at US academic institutions: a benchmark analysis. J Cancer Educ 2013;28:541-6.

7. McClelland S 3rd, Mitin T, Wilson LD, et al. Relationship Between Citation-Based Scholarly Activity of United States Radiation Oncology Residents and Subsequent Choice of Academic Versus Private-Practice Career. Int J 
Radiat Oncol Biol Phys 2018;101:46-8.

8. McClelland S 3rd, Mitin T, Jagsi R, et al. Importance of First and Second Authorship in Assessing Citation-Based Scholarly Activity of US Radiation Oncology Residents and Subsequent Choice of Academic Versus Private Practice Career. J Am Coll Radiol 2018;15:1322-5.

9. McClelland Iii S, Mitin T, Nabavizadeh N, et al. Use of the g-index for assessment of citation-based scholarly activity of United States radiation oncology residents and subsequent choice of academic versus private practice career. Rep Pract Oncol Radiother 2019;24:294-7.

Cite this article as: McClelland S 3rd, Murphy B, Jaboin JJ, Zellars RC. Gender-based analysis of pre-residency research productivity among a current United States radiation oncology resident class. Chin Clin Oncol 2021;10(5):52. doi: 10.21037/ cco-21-95
10. Ahmed AA, Hwang WT, Holliday EB, et al. Female Representation in the Academic Oncology Physician Workforce: Radiation Oncology Losing Ground to Hematology Oncology. Int J Radiat Oncol Biol Phys 2017;98:31-3.

11. Association of American Medical Colleges. More Women Than Men Enrolled in U.S. Medical Schools in 2017. Accessed on March 2, 2018. Available online: https://news.aamc.org/press-releases/article/applicantenrollment-2017/ 